\title{
Las cuatro voces de M. Serres: a propósito de la película El Archipiélago Carpaccio*
}

\author{
Piepre Samson \\ Traducción del francés al español de Luis Alfonso Paláu-Castaño \\ Universidad Nacional de Colombia, sede Medellín, Colombia \\ lapalau@gmail.com
}

Fue en Venecia, en el mes de junio, donde por requerimientos de una película sobre el pintor que Michel Serres retomaba ante la cámara los análisis de su incisivo libro Estéticas sobre Carpaccio (1975).

Película, cámara; el filósofo descubría hace treinta años (y creo que por primera vez) los imperativos y las trampas de las tomas, de la grabación de voz, a riesgo de su presencia en la pantalla. Ahora bien, en menos de una semana luego de hacerse un ocho-Michel Serres lo comprendió todo. Vi ante mi cámara una metamorfosis estupefactiva. Profesor que hesitaba el lunes, comediante confirmado el sábado, diez años de oficio iSin ninguna duda!... Por el dominio del gesto, de la voz, de la mirada, de la respiración sobre todo, se apoderó del cuadro de la imagen y del micrófono con evidencia y simplicidad; desde siempre había tuteado esta técnica, la cámara como una amiga, el micrófono como un hermano.

El visor es un espejo que se levanta, un cuadro vertical: la pantalla. Pero es también el jardín abierto a la profundidad, del otro lado de la ventana, allá donde uno puede pasear su cuerpo, y desplegar el espacio de una palabra. Es decir, el espacio del sentido, aquí el laberinto de Venecia, recorrido sin perderse al hilo del discurso para interrogar mejor las grandes figuraciones jerárquicas y misteriosas de Carpaccio. En algunos días, Michel Serres había hecho suyo este doble espacio.

Cómo citar: Samson, P. (2019). Las cuatro voces de M. Serres: a propósito de la película El Archipiélago Carpaccio. Ciencias Sociales y Educación, 8(16), 153-156. DOI: https://doi.org/10.22395/csye.v8n16a9

Traducción realizada por Luis Alfonso Paláu-Castaño. Agradecemos a la editorial L'Herne permitir el acceso del libro en francés para su versión, en partes, en español.

Recibido: 10 de agosto de 2019.

Aprobado: 20 de septiembre de 2019.

** Realizador documentalista. Principales realizaciones: "Diderot, Salones" (1972); "Malraux y la condición humana" (1974); "el Archipiélago Carpaccio" (rodado en Venecia y París en 1977); "Bajo las palabras, la lingüística" (1982) galardonada con el Premio especial del Jurado CSI "La Villete; el Reverso de la forma: N. de Staël" (1983), Gran Primer premio del Festival internacional "Film d'art; La estación del ferrocarril en el Museo" (1987), Primer Premio documental Ciudad de París; "Palabras y política" (2000). Docente de cine: CIES-Sorbona, ENS Louis Lumière, Middlebury College, Institute of European Studies Abroad París. 
Por mi oficio a menudo he filmado profesores de los más eminentes. Muchos se resisten, suben el tono, se espantan con la mirada ("¿Dónde están mis estudiantes?”), y se ponen tiesos (“¿Qué es esa malvada caja negra que me traga silenciosamente veinticuatro veces por segundo? ¿Qué va a hacer usted con mi doble... despedazarlo en el montaje?"). Porque tienen demasiado miedo a ser desposeídos, a esos profesores no les funciona. La cátedra es triste. iAy! Han leído todos los libros.

En Venecia no pasó nada de esto. Durante esa semana de filmación cuatro generosos Michel Serres se sucedieron delante del objetivo, cada uno despedía al anterior: el profesor, el predicador, el seductor, el viajero. Los cuatro gascones por supuesto. Uno para todos, todos para uno.

\section{El profesor}

De pie ante el gran "San Jorge y el dragón" de la capillita enteramente en madera, llena de cirios y olorosa, de San Giorgio degli Schiavoni, enfático habla el maestro con la voz un poco fuerte, como la tienen todos los profesores que trabajan en anfiteatros amplios. Una demostración rigurosísima: a la izquierda el dragón, a la derecha el caballero, forman una pareja cómplice (con la misma coraza), equilibrio eterno de la guerra-espectáculo para disimular mejor la verdadera tragedia, con sus espectadores en lo alto, en el balcón y sus trozos de cadáveres esparcidos en el lodo bajo los combatientes de ópera. El profesor Serres diseca el cuadro con la autoridad de un gran maestro de cirugía: bisturí en la voz, laser en la mirada.

Es verdad que somos en parte responsables de esta tiesura: se le pidió que no se moviera ni una pulgada durante la filmación. Imagino que fue un verdadero suplicio cuando uno ha visto a Michel Serres recorrer a pasos largos, alegremente, el estrado de la Sorbona, improvisando sobre la obra maestra desconocida de Balzac.

\section{El predicador}

Filmamos ahora con la cámara hacia el San Agustín que está a todo el frente del San Jorge. Cambia de voz, de tono, entramos en las órdenes, pero ante todo en la celda silenciosa del doctor de la iglesia. Se escucharía pasar un ángel. Tengo ganas de quitarme los zapatos. La voz de Michel Serres se hace más retenida y vibrante. De oficio se suma al combate de san Agustín contra el maniqueísmo. No sube a la cátedra, eso era antes en la Sorbona. No, como el propio san Agustín, renuncia a su cátedra de elocuencia para convertirse a la suave palabra inspirada y a la luz blanca. Michel Serres cuenta exactamente el número de obras que hay en la celda: noventa y cuatro, la totalidad del corpus de san Agustín 
que levanta por última vez la pluma, y su mirada hacia la ventana, "fuera del campo cinematográfico".

La voz de nuestro filósofo, llena de respeto por esta obra de fe y música, se hace ascética, mística, y nos toma por testigos, firmemente apologético en medio de los verdes y los rojos, sordos y apasionados del cuadro intenso de Carpaccio. Qué cosa acaba de aparecer en la voz del filósofo: la convicción, que nunca engaña. Quiere convertir a los ignorantes y descreídos que somos, mariposas enceguecidas, agitadas en la luz de nuestros proyectores.

\section{El seductor}

En la mañana del tercer día, el docto le deja definitivamente el sitio al hombre que mira las mujeres: quiero hablar de las "Dos cortesanas", el cuadrito sublima (sin duda un fragmento) del Museo Correr. Se trata quizás de la misma mujer "en la mañana y en la tarde de su vida". El filósofo deshoja voluptuosamente los diferentes velos del sentido: símbolo, combinatoria, estructura, semiótica. Toda una maquinaria de teatro, dice él. Michel Serres nos lleva a franquear una a una las puertas del saber, de las leyes para tratar de entrever el sentido (o la falta de sentido) último: la identidad del cuadro, lo mismo. Como un secreto más allá de las montañas.

Nada de producir un discurso para ponerlo por delante. Reducir un discurso para convertirlo en migajas que se dejan bien lejos; de ninguna manera. Más bien seducir, es decir, llevar aparte, en el sentido propio, lejos de los análisis canónicos del historiador del arte o el especialista en la "piadosa iconología" para analizar libremente.

Michel Serres nos conduce por "el jardín de los senderos que se bifurcan" del sentido hacia un lugar separado, por tanto seductor; hacia una geografía sonriente donde florecen todas las historias del mundo. Sherazada cuenta, sigue contando, el filósofo superpone esos cuentos, analiza, continúa analizando, luego borra todo sonriente: "aquí no hay más que belleza para ver en medio de los colores".

\section{El viajero}

El verdadero Michel Serres, el de los barcos y la ecúmene, puede por fin aparecer.

Instalados con nuestra cámara en una góndola, recorremos el laberinto de Venecia ritmado por la sombra de los puentes y el reflejo de los Palacios. El filósofo amplía sus afirmaciones retomando elementos de su texto Discurso y recorrido (Serres, 1977). Al ritmo del remo batiente por estribor atrás, él "conecta 
lo desconectado" y "desconecta lo conectado" sin fin, tal como "Ulises yendo de isla en isla", mientras Penélope "hace y deshace su tejido" 12 ...

Estas tomas, ante todo las de sonido sobre la esbelta góndola, de repente me permiten comprender la magia invisible de Venecia: en esta ciudad sin vehículos, los más pequeños ruidos son repercutidos y amplificados por las altas murallas apretadas, la concha de los puentes, el leve temblor del agua. Se puede escuchar y grabar hasta el choque de una cucharita en una taza de porcelana en el fondo de un apartamento iCon una precisión increíble! Ninguna ciudad del mundo ofrece un placer tal al oído.

La voz de Michel Serres se destaca perfectamente sobre este encaje sonoro. Escucho y saboreo aunque no lo comprenda todo. Me viene esa reflexión de Jacques Prévert a propósito de su amiga Arletty: "los actores tienen algo terriblemente misterioso... No se piensa en la voz de las gentes. Es la voz la que cuenta. Se dice - de los actores_que ellos hablan, pero ellos cantan igualmente, y no se escucha que cantan. Es un canto interior".

Michel Serres, dice Maurice Druon, tiene el genio de la lengua. Montaigne. Es ante todo una voz y tras esa voz se puede adivinar el "canto interior". Aquí ya no se puede decir nada, es el secreto hundido de cada uno. Es el suyo, de las orillas del Garona al Muelle de Conti y más allá de los mares. La película permite entrever ese "canto interior", y me ofrece la certidumbre (¿La ilusión?) de comprender mejor a un escritor para mí a veces hermético en su escrito.

En el curso de la filmación hemos podido observar cómo la música de esta voz se multiplica, o se reparte entre el científico, el predicador, el cuentista y el explorador. De Leibniz y Julio Verne, va de los ángeles y Balzac.

La unidad de esta palabra es quizás, en definitiva, la de un cuarteto vocal: un bajo, "bajo profundo o noble" como le conviene a la Sorbona; un barítono de convento, entre prédica y canto gregoriano; un tenor lírico llamado de "mediocarácter" con timbre encantador, que tanto debía gustar antaño en la ópera de Toulouse; y finalmente, envolviendo y sosteniendo las tres voces, el coro de marineros que se eleva hacia mar adentro.

Cuatro voces que trabajan al unísono: el archipiélago Michel Serres.

\section{Referencias}

Serres, M. (1977). Hermes IV: la Distribution. Paris: Minuit.

Serres, M. (1992). Estéticas sobre Carpaccio (Ma. Gómez, trad.). Medellín: Universidad Nacional de Colombia. (Obra original publicada en 1975)

1 "De esta extensión descompuesta, muda e inviolable, hacer la puerta del Oriente y del Occidente. Despertar a Grecia, acoger a Egipto, recibir el Sol levante, hablar la multiplicidad de las lenguas... Milagro de Venecia: localmente cerrada, proyección del comercio mundial. Versión espacial, económica y lingüística, de la conversación" (Serres, 1992). 